\title{
Duodenogastric reflux: clinical and therapeutic aspects
}

\author{
Adam Szarszewski, Maria Korzon, Barbara Kamiñska, Piotr Lass
}

\begin{abstract}
Background-Duodenogastric reflux is believed to cause damage to gastric mucosa. Most reports on this disorder concern adult patients.

Patients and methods-1120 children with abdominal pain were studied; endoscopic features of duodenogastric reflux were found in 92 patients. To confirm the diagnosis of duodenogastric reflux, cholescintigraphy (Tc99-HEPIDA) was performed. Children with confirmed duodenogastric reflux by scintigraphy were given a prokinetic drug (cisapride).

Results-Endoscopic features of duodenogastric reflux were found in 92 children; the diagnosis was confirmed by scintigraphy in 59 patients. There was no significant difference in the severity of inflammation in gastric mucosa compared with the control group, whereas significantly fewer of these patients were infected with Helicobacter pylori. There was no correlation between regions of isotope accumulation and inflammatory lesions in the stomach. The prokinetic drug (cisapride) helped eliminate or greatly reduce duodenogastric reflux in children. Conclusions-When endoscopic features of duodenogastric reflux are found the final diagnosis should be based on an examination that does not itself influence the motility of the gastrointestinal tract: cholescintigraphy seems to be a useful method. However, because the use of milk as a test meal affects the scintigraphic image, there was no correlation between the area of isotope accumulation and the localisation of inflammatory lesions in the stomach. Duodenogastric reflux seems to be less important as a cause of inflammatory lesions than other factors (such as genetic predisposition, stress, etc). Prokinetic drugs have a beneficial influence on treatment results in children with inflammatory lesions of gastric mucosa with duodenogastric reflux.

(Arch Dis Child 1999;81:16-20)
\end{abstract}

Keywords: duodenogastric reflux; cholescintigraphy; cisapride

Duodenogastric reflux (bile reflux) can cause gastric mucosa inflammation and/or ulceration, ${ }^{1-5}$ intestinal metaplasia in the stomach, ${ }^{6}$ and increased risk of gastric cancer. ${ }^{7}$ Bile reflux is a result of impaired motility of the antroduodenal region (spontaneous reflux). ${ }^{89}$ In adults, it can also be a complication of par- tial gastrectomy, ${ }^{451011}$ but this operation is very rare in children. The diagnosis of duodenogastric reflux is a complex one. In adults there are no pathognomonic clinical symptoms suggesting bile reflux. ${ }^{4}$ It is usually discovered during endoscopy, but it has been observed that the process of inserting an endoscope generates retropulsive waves and leads to bile reflux. ${ }^{42}$ Morphological changes in gastric mucosa cannot verify the diagnosis either. ${ }^{12}$ Thus, several additional methods have been developed, such as measuring the concentrations of bile acids ${ }^{13}$ and sodium in gastric contents, ${ }^{14}$ pH-metry, ${ }^{15}$ and Doppler ultrasonography. ${ }^{16}{ }^{17}$ Dynamic cholescintigraphy, which has been used successfully for several years, allows the evaluation of the grade of reflux (reflux index), and a modification of the method introduced by Mackie et al, ${ }^{18}$ with milk as the test meal, appears to be particularly useful.

Duodenogastric reflux can also occur during endoscopy of the upper gastrointestinal tract in children and usually the diagnosis has not been confirmed with other methods. There are also no data on the incidence of bile reflux and how often it is responsible for recurrent abdominal pain in children. ${ }^{19}$ The correlation between severity of reflux and inflammatory lesions in gastric mucosa has not been analysed and there are very few studies on the role of prokinetic drugs in limiting bile reflux in children. ${ }^{20}{ }^{21}$

In our study, we aimed to: (1) determine the incidence of duodenogastric reflux in children suffering from chronic, recurrent abdominal pain; (2) assess the possible relation between the degree of the reflux and the severity of inflammatory lesions in the mucosa of stomach and duodenum; (3) observe whether regions of the highest isotope accumulation on cholescintigraphy correspond to the areas of the most severe inflammation in the stomach; and (4) observe whether prokinetic drugs combined with anti-inflammatory agents improve symptoms and signs in patients with gastritis and duodenitis who suffer from bile reflux.

\section{Materials and methods}

We studied 1120 children who were diagnosed as having recurrent abdominal pain and who presented to the department of paediatrics, paediatric gastroenterology, and oncology at the Medical University of Gdañsk from 1993 to 1996 inclusive. All children had an endoscopic examination of their upper gastrointestinal tract by Olympus GIF-PQ 20 or GIF-PQ 10 endoscope. We examined the oesophagus, stomach, and duodenal cup and the severity of inflammation in the stomach 


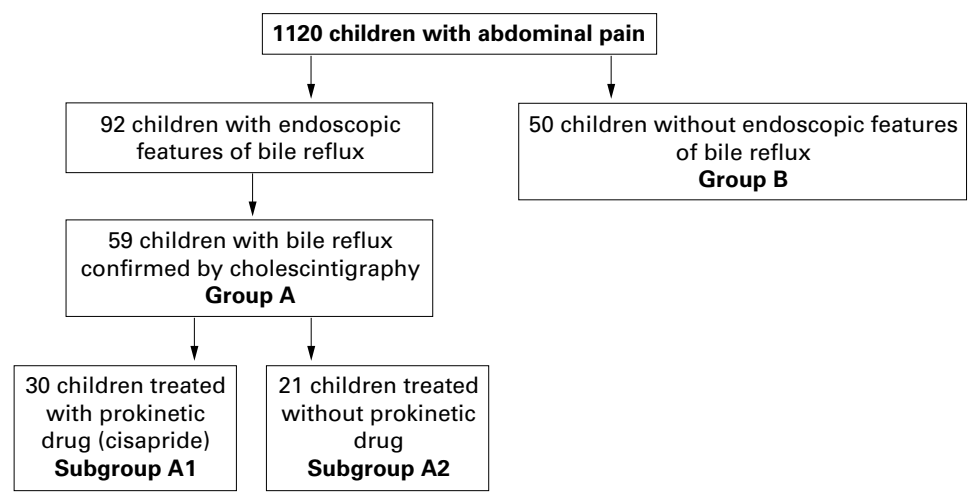

Figure 1 Criteria for including children with chronic abdominal pain in our study on duodenogastric reflux.

Table 1 Results of endoscopic and histological evaluation of gastric mucosa according to the presence or absence of bile reflux

\begin{tabular}{|c|c|c|c|c|c|c|c|c|}
\hline & \multicolumn{4}{|c|}{$\begin{array}{l}\text { Group A (bile reflux) } \\
(n=59)\end{array}$} & \multicolumn{4}{|c|}{$\begin{array}{l}\text { Group B (no bile reflux) } \\
(n=50)\end{array}$} \\
\hline & \multicolumn{8}{|c|}{ Stage of inflammatory lesions according to Sydney criteria } \\
\hline & $I$ & $I I$ & III & $I V$ & $I$ & II & $I I I$ & IV \\
\hline \multicolumn{9}{|l|}{ Body of the stomach } \\
\hline Endoscopic appearance & 38 & 6 & 9 & 6 & 45 & 2 & 2 & 1 \\
\hline Histology & 45 & 12 & 2 & 0 & 42 & 7 & 0 & 1 \\
\hline \multicolumn{9}{|l|}{ Antrum } \\
\hline Endoscopic appearance & 1 & 22 & 29 & 7 & 3 & 17 & 27 & 3 \\
\hline Histology & 22 & 30 & 5 & 2 & 24 & 23 & 1 & 2 \\
\hline
\end{tabular}

mucosa was assessed visually according to the Sydney scale. ${ }^{22}$ The following features were considered: the presence of normal blood vessels, the presence of oedema, erythema, exudate, erosion, hypertrophy, or atrophy of gastric mucosal fold. We graded the degree of progression according to a scale from I to IV (grade I, no changes; grade II, mild changes; grade III, moderate changes; grade IV, severe changes). In the duodenum we evaluated the degree of visual inflammation as mild, moderate, or severe. The presence of oedema, erythema, exudate, erosion, and duodenal mucosa hypertrophy were considered. We performed the urease test (CLO-test) in all patients to exclude or confirm Helicobacter pylori infection. We took two biopsy specimens from the stomach (the body and the antrum) and one from the duodenal cap for morphological assessment from all children. In the stomach specimens we assessed histological inflammation according to the Sydney scale. We considered the following features: the intensivity and activity of inflammation, the degree of gastric gland atrophy, and the presence of metaplasia. We graded the degree of progression according to a scale from I to IV (as above). In the duodenum we considered the following features: the intensivity and activity of inflammation and the presence of metapla- sia. We assessed the degree of progression as mild, moderate, and severe.

In children with endoscopic suspicion of bile reflux, we performed dynamic cholescintigraphy to confirm the diagnosis of bile reflux.

According to the result of endoscopic examination, we initially diagnosed bile reflux in 92 children. Children were fasted before cholescintigraphy. We administered the radiopharmaceutical agent (technetium-99m; HEPIDA) intravenously, at 3-4 mCi (111-148 MBq)/ dose and acquisitions were carried out every five minutes, each lasting one minute. After the fifth measurement, we gave the children 150-200 ml of condensed cows' milk to drink. After the 12th measurement, we gave $2 \mathrm{mCi}$ $(74 \mathrm{MBq})^{99 \mathrm{~m}} \mathrm{Tc}$ orally to detect the gastric field.

Evaluation of the results of cholescintigraphy was based on: morphological features (timeactivity curves over the gastric field), and the reflux index calculated by dividing the number of gastric counts obtained during the exposure by the sum of the gastric and intestinal counts.

We randomly selected a control group of 50 from the group of children without endoscopic features of bile reflux. Some patients with bile reflux, confirmed by scintigraphy, received the prokinetic drug (cisapride) in addition to antiinflammatory drugs (tripotassium dicitratobismuthate and amoxicillin and metronidazole in children with $H$ pylori). To assess the efficacy of cisapride, we divided patients randomly into two groups: a group of children treated with cisapride and those who did not receive cisapride. Figure 1 gives a summary of the allocation of children to various groups. We gave cisapride for six weeks, tripotassium dicitratobismuthate for four weeks, amoxicillin for seven days, and metronidazole for 14 days. We performed the repeat scintigraphy three weeks after the end of treatment.

We analysed results with the $\chi^{2}$ test and Mann-Whitney test.

Our study was approved by the research advisory committee of the Medical University of Gdañsk.

\section{Results}

Among 1120 children, 92 (8.21\%) were found to have bile reflux on endoscopy. The presence of reflux was confirmed by scintigraphy (group A) in 59 patients comprising $5.27 \%$ of the children who had abdominal pain. The range of the reflux index was 2-20\% (median, $5.6 \%$ ).

Group B consisted of 50 patients chosen at random from patients who did not have bile reflux at endoscopy. In group A there were 43 girls and 16 boys and in group B there were 22

Table 2 Results of endoscopic and histological evaluation of duodenal mucosa according to the presence or absence of bile reflux

\begin{tabular}{|c|c|c|c|c|c|c|c|c|}
\hline \multirow[b]{2}{*}{ Inflammatory lesions } & \multicolumn{4}{|c|}{ Group $A$ (bile reflux) $(n=59)$} & \multicolumn{4}{|c|}{ Group B (no bile reflux) $(n=50)$} \\
\hline & No changes & Mild & Medium & Severe & No changes & Mild & Medium & Severe \\
\hline Endoscopic appearance & 24 & 30 & 5 & 0 & 25 & 21 & 2 & 2 \\
\hline $\begin{array}{l}\text { Stage of inflammatory lesions } \\
\text { (Sydney criteria) }\end{array}$ & $I$ & $I I$ & $I I I$ & $I V$ & $I$ & $I I$ & $I I I$ & $I V$ \\
\hline Histology & 22 & 31 & 6 & 0 & 21 & 25 & 1 & 3 \\
\hline
\end{tabular}


Table 3 Regions of accumulation of radiopharmaceutical agent and localisation of inflammatory lesions in the stomach

\begin{tabular}{llcl}
\hline $\begin{array}{l}\text { Region of accumulation of } \\
\text { radiopharmaceutical agent }\end{array}$ & $\begin{array}{l}\text { Number of } \\
\text { children }\end{array}$ & $\begin{array}{l}\text { Gastritis corporalis } \\
\text { chronica }\end{array}$ & $\begin{array}{l}\text { Gastritis antralis } \\
\text { chronica }\end{array}$ \\
\hline Antrum & 20 & 7 & 10 \\
Cardia & 24 & 3 & 17 \\
Even dispersion & 15 & 4 & 10 \\
Total & 59 & 14 & 37 \\
\hline
\end{tabular}

girls and 28 boys. In group A the children's ages ranged from 4 to 17 years, with a mean (SD) of 12.25 (2.58) years. In group B the children's ages ranged from 5 to 17 years (mean, 11.58 years; SD, 3.08). No symptoms were found to be characteristic enough to identify those with bile reflux from the group of patients with recurrent abdominal pain.

Table 1 gives the results of endoscopic and histological examination of the stomach. More severe lesions were observed endoscopically in the body of the stomach in patients in group A than in group B $(p<0.01)$. However, the frequency of severe lesions in the antrum was similar in the two groups. The severity of histological inflammation was also similar in the two groups (table 1). Helicobacter pylori infection was detected in 15 children from group A and 27 from group B. Children who did not have bile reflux were significantly more often infected with $H$ pylori compared with children who had bile reflux $(\mathrm{p}<0.005)$. Table 2 gives the results of endoscopic and histological evaluation of the duodenum. There was no significant difference in the distribution of the severity of lesions between the two groups. In group A (children with reflux) we also analysed scintigraphic images. There were three types of distribution of the radiopharmaceutical agent: (1) the isotope was distributed evenly in the stomach; (2) the isotope accumulated in the antrum; and (3) the isotope accumulated in the cardiac region.

Statistic analysis ( $\chi^{2}$ test) showed no correlation between regions of accumulation of radiopharmaceutical agent and localisation of histologically assessed inflammatory lesions in the stomach (table 3).

We found that intensity of inflammation in the stomach and duodenum did not depend on the grade of reflux (table 4).

In our study, there was a lack of correlation between areas of the isotope accumulation and localisation of histologically assessed inflammatory lesions in the stomach. To explain this phenomenon, we carried out the following experiment. We performed cholescintigraphy on three male adult volunteers in the same way that it was performed on the children in our study. The contents of the stomach, containing $200 \mathrm{ml}$ condensed cows' milk as a test meal and the radiopharmaceutical agent, were evacuated

Table 4 Reflux index (Ri) and inflammatory changes in the stomach

\begin{tabular}{llll}
\hline Ri range & $\begin{array}{l}\text { Number of } \\
\text { children }\end{array}$ & $\begin{array}{l}\text { Gastritis corporalis } \\
\text { chronica }\end{array}$ & $\begin{array}{l}\text { Gastritis antralis } \\
\text { chronica }\end{array}$ \\
\hline $1-5.9 \%$ & 30 & 10 & 20 \\
$6-10.9 \%$ & 15 & 2 & 10 \\
$11-20 \%$ & 14 & 2 & 7 \\
Total & 59 & 14 & 37 \\
\hline
\end{tabular}

A
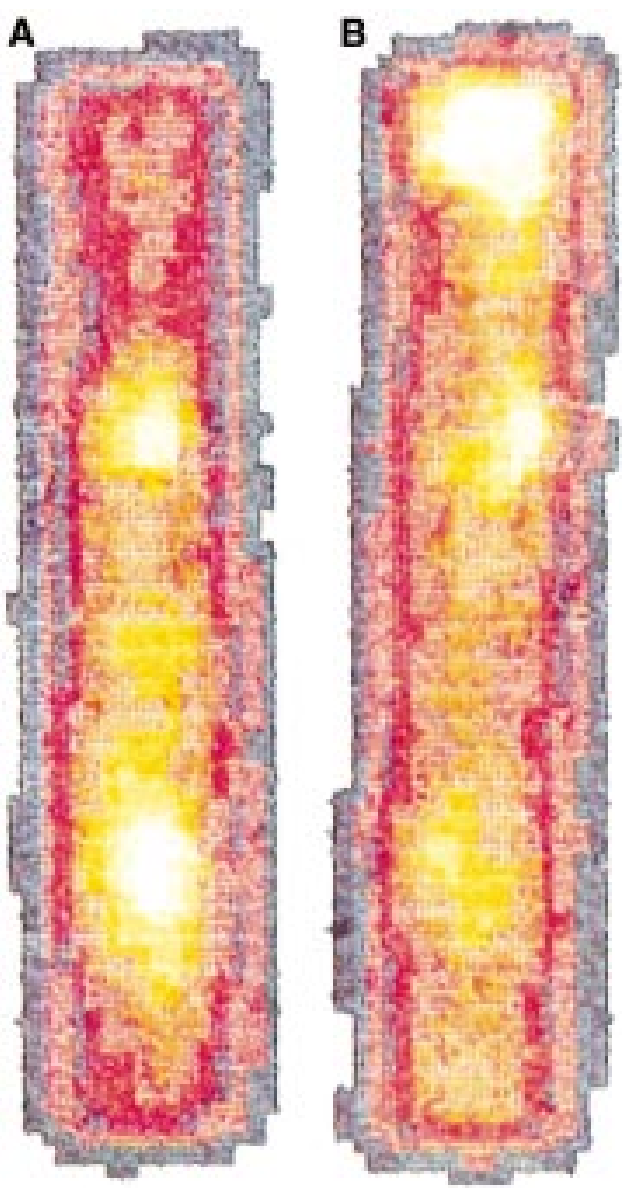

Figure 2 Distribution of radiopharmaceutical agent in the distortion dish filled with gastric contents and reflux material. (A) Immediately after gastric contents intake, (B) 15 minutes after gastric contents intake. Red, low radioactivity; yellow, high radioactivity.

and placed in a glass distortion dish. The distortion dishes were examined by means of a $\gamma$-camera. The pictures taken immediately after placing into the glass distortion dish and those taken later show the tendency of the radiopharmaceutical agent to gather at the top. Analysis of the isotope distribution revealed that the isotope particles, bound to digested milk, accumulated in the upper part of the dish (fig 2). This phenomenon is an artefact of the scintigraphic examination and is caused by using milk as the test meal.

Children from group A, who had gastritis and bile reflux, had anti-inflammatory drugs administered. Initially, 36 of the 59 were treated additionally with cisapride, but six were lost at follow up and so only 30 are reported here.

The evaluation of treatment with cisapride was based on two indices: the clinical improvement and alterations of reflux index. Because most of the patients did not consent to a further endoscopy, an analysis of changes in the mucosa of the stomach and duodenum during the course of treatment was not possible.

In those receiving cisapride, the initial reflux index ranged from $2 \%$ to $20 \%$ (median, $5.9 \%$ ) and the corresponding results in those not receiving cisapride ranged from $2.2 \%$ to $18 \%$ (median, 6.4\%). After cisapride treatment 18 
children did not have any features of bile reflux (median, 0\%). In five children, who were not treated with cisapride, there was no bile reflux (median, 6\%). Statistic analysis (MannWhitney test) showed that treatment with cisapride reduces the incidence of bile reflux $(\mathrm{U}=192.5 ; \mathrm{p}<0.01)$.

Clinical improvement was seen in 28 children who were treated with cisapride and in 18 children who were not treated with cisapride.

Cisapride was well tolerated by most of the patients; only two children complained of a worsening of abdominal pain, which made us decide to eliminate the drug from the treatment scheme in these patients. Other side effects were not noted.

\section{Discussion}

Endoscopic criteria of bile reflux in children are the same as in adults. As has been shown in other papers, they are not sufficient to establish the diagnosis. Other methods allow verification of the endoscopic diagnosis in $30-40 \%$ of cases. ${ }^{4}$ Similar results were obtained in our study (verification of endoscopic diagnosis in $64.1 \%$ cases).

Of special interest is the influence of bile reflux on the gastric mucosa. Although many authors have observed the correlation between the presence of bile reflux and intensity of inflammatory lesions, ${ }^{1-46}$ there are also many papers in which such correlations have not been found..$^{123}{ }^{24}$ It has been mentioned before that the concentration of bile acids in patients with bile reflux is very rarely as high as in experimental conditions. ${ }^{4}$ High concentrations of bile acids and lysolecithine are seen mainly in patients who have had surgery of distal parts of the stomach, and there were no such cases included in our study. The reflux index was also quite low in the children that we examined. In some studies, reflux indexes as high as $1-70 \%$ have been reported, ${ }^{4}$ and they are definitely higher in patients who have undergone partial gastrectomy (usually reflux index $>20 \%) .{ }^{25}$ In children, the reflux grade is comparatively low and this is probably why it does not have a crucial influence on inducing mucosal lesions. Hence, there must be some other factors that are responsible for inflammatory lesions in the stomach and duodenum in children. Some of them are widely known, such as genetic predisposition, psychological factors, and $H$ pylori infection. In our study, the first two factors seem to dominate. A family history of upper gastrointestinal tract disorders was very common. In as many as $42.4 \%$ of the families, we found a history of gastric or duodenal ulceration. Our paper confirms the importance of psychological factors in the development of gastritis and duodenitis.

Helicobacter pylori infection has considerably less influence on the development of inflammatory lesions in children with bile reflux. These patients were significantly less often infected with the bacterium than children without reflux. This is probably because of the alkalisation of gastric contents in children with bile reflux, which may make colonisation by $H$ pylori more difficult. Other authors have also noted this phenomenon in adults. ${ }^{56}$

During the scintigraphic verification of bile reflux in children we noted that regions of isotope accumulation did not correspond to the regions of the most severe inflammation diagnosed endoscopically and morphologically. It has been shown that Mackie's modification $^{18}$ of cholescintigraphy results in producing artefacts, which makes interpretation more difficult. Further research is needed to find a different test meal, so that this useful diagnostic method could be applied more widely. Treatment regimens for children with bile reflux have not been established yet. In our study we have added a prokinetic drug to the anti-inflammatory agent in the treatment. Cisapride was chosen because it has very few side effects and it is effective in improving gastroduodenal coordination. ${ }^{20} 28$ The drug was well tolerated, as has been noted in other reports. Our study proved its efficacy in eliminating bile reflux.

There is still one question that remains to be answered: whether or not, and in what situations, a prokinetic drug should be given. Our study does not enable us to draw conclusions of clinical importance, which would help the physician to make decisions about treatment. The fact that these drugs are also used in so called functional dyspepsia and in gastritis or gastric ulceration makes the problem even more complex. Usually, in these cases, the cause of the disorder is an impairment of evacuation of gastric contents, and the prokinetic drugs help to maintain proper evacuation of the retained food. Because of this, many authors suggest administering prokinetic preparations in the treatment of gastritis and/or gastric ulceration and in so called functional dyspepsia. ${ }^{29-32}$ This problem undoubtedly requires further evaluation.

CONCLUSIONS

- Gastroduodenal reflux was diagnosed endoscopically in 92 of 1120 children with recurrent abdominal pain, and cholescintigraphy confirmed its presence in 59 of these children. This suggests the need to verify the endoscopic diagnosis with other methods

- There was no significant difference in the intensity of inflammatory lesions in the mucosa of the stomach and duodenum between children with bile reflux and children without this disorder. This suggests that there might be other factors that are important in children, such as genetic predisposition and psychogenic factors

- The isotope method applied to verify the endoscopic diagnosis carries a potential error because of the use of milk as the test meal. It causes lack of correlation between the areas of the most intensive accumulation of the isotope and the localisation of inflammatory lesions in the stomach

- Administration of a prokinetic drug (cisapride) has a major influence on decreasing reflux index. 
1 Bechi P, Amorosi A, Mazzanti R, Romagnoli P, Tonelli L. Gastric histology and fasting bile reflux after partial

2 Bechi P, Amorosi A, Mazzanti R, et al. Reflux-related gastric mucosal injury is associated with increased mucosal histamine content in humans. Gastroenterology 1993;104:105763.

3 Masci E, Testoni PA, Fanti L, Guslandi M, Zuin M, Tittobello A. Duodenogastric reflux: correlations among bile acid pattern, mucus secretion, and mucosal damage. Scand f Gastroenterol 1987;22:308-12.

4 Niemelä S, Karttunen T, Heikkilä J, Lehtola J. Characteristics of reflux gastritis. Scand F Gastroenterol 1987;22:34954.

5 Offerhaus GJ, Rieu PN, Jansen JB, Joosten HJ, Lamers CB. Prospective comparative study of the influence of postoperative bile reflux on gastric mucosal histology and Campylobacter pylori infection. Gut 1989;30:1552-7.

6 Sobala GM, O'Connor HJ, Dewar EP, King RF, Axon AT, Dixon MF. Bile reflux and intestinal metaplasia in gastric Dixon MF. Bile reflux and intestinal m
mucosa. Clin Pathol 1993;46:235-40.

7 Hashimoto K, Kakegawa T, Takeda J, et al. The effect of bile juice reflux on the development of remnant stomach carcijuice reflux on the development of

8 Code CF, Schlegel JF. The gastrointestinal interdigestive housekeeper: motor correlates of the interdigestive myoelectric complex of the dog. In: Daniel EE, ed. Proceeding of the fourth international symposium on gastrointestinal motility. Vancouver: Mitchell Press, 1973:631-3.

9 Testoni PA, Fanti L, Passaretti S, Masci E, Guslandi M, Tittobello A. Interdigestive motility pattern in subjects with duodenogastric bile reflux. Scand 7 Gastroenterol 1987;22: 757-62.

10 Ritchie W. Alkaline reflux gastritis: a critical reappraisal. Gut 1984;25:975-87.

11 Tolin RM, Malmud LS, Stelzer F, et al. Enterogastric reflux in normal subject and patients with Billroth II gastroenterostomy. Gastroenterology 1979;77:1027-33.

12 Stein HJ, Smyrk TC, DeMeester TR, Rouse J, Hinder RA Clinical value of endoscopy and histology in the diagnosis of duodenogastric reflux disease. Surgery 1992;112:796803.

13 Hoare AM, Keighley MRB, Starkey B. Measurement of bile acid in fasting gastric aspirates: an objective test for bile reflux after gastric surgery. Gut 1978;19:166-9.

14 Smythe A, Bird NC, Johnson AG. Continuous monitoring of sodium ion concentration in the human stomach-a new technique for the detection of duodenogastric reflux. Digestion 1992;52:20-5.

15 Fuchs KH, DeMeester TR, Hinder RA, Stein HJ, Barlow AP, Gupta NC. Computerized identification of pathologic duodenogastric reflux using 24 hour gastric $\mathrm{pH}$ monitoring. Ann Surg 1991;213:13-20.
16 Fujimura J, Haruma K, Hata J, Yamanaka H, Sumii K, Kajiyama G. Quantitation of duodenogastric reflux and antral motility by color Doppler ultrasonography. Study in healthy volunteers and patients
Gastroenterol 1994;29:897-902.

17 Hausken T, Ødegaard S, Berstad A. Antroduodenal motility studied by real-time ultrasonography. Gastroenterology 1991;100:59-63.

8 Mackie CR, Wisbey ML, Cuschieri A. Milk ${ }^{99} \mathrm{Tc}^{\mathrm{m}}-\mathrm{EHIDA}$ test for enterogastric bile reflux. Br f Surg 1982;69:101-4.

19 Markowitz JF. Duodenogastric reflux: the state of the art. $\mathcal{F}$ Pediatr Gastroenterol Nutr 1990;10:287-9.

20 Cucchiara S, Bortolotti M, Colombo C, et al. Abnormalities of gastrointestinal motility in children with nonulcer dyspepsia and in children with gastroesophageal reflux disease. Dig Dis Sci 1991;36:1066-73.

21 Cucchiara S, Bortolotti M, Minella R, et al. Children with functional gastrointestinal symptoms: effects of cisapride on fasting antroduodenal motility, gastric emptying of on fasting antroduodenal motility, gastric emptying of
liquids and symptoms. Eur $\mathcal{F}$ Gastroenterol Hepatol 1992;4:
$627-33$.

22 Misiewicz JJ. The Sydney system: a new classification of gastritis. $\mathcal{F}$ Gastroenterol Hepatol 1991;6:207-8.

23 Cheli R, Giacosa A. Reflux gastritis and dysplasia. Scand 7 Gastroenterol Suppl 1984;92:200-2.

24 Kellosalo J, Alavaikko M, Laitinen S. Effect of biliary tract procedures on duodenogastric reflux and the gastric mucosa. Scand f Gastroenterol 1991;26:1272-8.

25 Xynos E, Vassilakis J.S, Fountos A, Pechlivanides G, Karkavitsas N. Enterogastric reflux after various types of antiulcer gastric surgery: quantitation by $99 \mathrm{mTc}-\mathrm{HIDA}$ scintigraphy. Gastroenterology 1991;101:991-8.

26 Lynch DA, Mapstone NP, Clarke AM, et al. Cell proliferation in the gastric corpus in Helicobacter pylori associated gastritis and after gastric resection. Gut 1995;36:351-3.

27 Cucchiara S. Cisapride therapy for gastrointestinal disease. 7 Pediatr Gastroenterol Nutr 1996;22:259-69.

28 Lux G, Katschinski M, Ludwig S, Lederer P, Ellermann A, Domschke W. The effect of cisapride and metoclopramide on human digestive and interdigestive antroduodenal motility. Scand 7 Gastroenterol 1994;29:1105-10.

29 Behrns KE, Sarr MG. Diagnosis and management of gastric emptying disorders. Adv Surg 1994;27:233-55.

30 Holtmann G, Talley NJ. Functional dyspepsia. Current treatment recommendations. Drugs 1993;45:918-30.

31 Van Outryve M, De Nutte N, Van Eeghem P, Gooris JP. Efficacy of cisapride in functional dyspepsia resistant to domperidone or metoclopramide: a double-blind, placebocontrolled study. Scand f Gastroenterol Suppl 1993;195:47-

32 Waldron B, Cullen PT, Kumar R, et al. Evidence for hypomotility in non-ulcer dyspepsia: a prospective multifactorial study. Gut 1991;32:246-51. 